\title{
Analisis tingkat motivasi belajar dan berlatih pada atlet-pelajar PPLOP Jawa Tengah tahun 2020
}

\author{
Agam Akhmad Syaukani *, Nur Subekti, Muhad Fatoni \\ Program Studi Pendidikan Olahraga, Fakultas Keguruan dan Ilmu Pendidikan, Universitas \\ Muhammadiyah Surakarta. Jalan Ahmad Yani, Pabelan, Kartasura, Surakarta 57162, Indonesia \\ * Corresponding Author. Email: aas622@ums.ac.id
}

Received: 18 June 2020; Revised: 5 August 2020; Accepted: 14 August 2020

\begin{abstract}
Abstrak: Pemerintah daerah melalui dinas pemuda dan olahraga memiliki program pemusatan latihan bagi atlet pelajar setingkat SMA yang bertajuk Pusat Pendidikan dan Latihan Olahraga Pelajar (PPLOP). Penelitian ini bertujuan untuk mengetahui tingkat motivasi atlet-pelajar PPLOPD Jawa Tengah dalam berlatih dan belajar di sekolah. Penelitian ini melibatkan 36 atlet dari cabang olahraga beregu. Metode survey deskriptif kuantitatif presentase digunakan untuk menjabarkan tingkat motivasi latihan (ML) dan motivasi belajar (MB). Uji beda juga dilakukan untuk mengetahui perbedaan tingkat ML dan MB antara pemain inti dan pemain cadangan pada sampel yang dilibatkan. Hasilnya sebanyak 47\% atlet memiliki tingkat MB yang tinggi, $39 \%$ dalam tingkat sedang, dan 14\% tergolong memiliki tingkat MB rendah. Tingkat ML dalam kategori tinggi $11,5 \%$, kategori sedang $77 \%$, dan kategori rendah $11,5 \%$. Dalam uji beda yang dilakukan diketahui tidak ada perbedaan yang signifikan antara tingkat ML dan MB $(p>0,05)$ pada pemain inti dan pemain cadangan. Hal ini menunjukkan bahwa mayoritas atlet memiliki motivasi belajar yang tinggi, namun di sisi lain mayoritas dari mereka tidak memiliki motivasi latihan yang tinggi sehingga fakta ini dapat dijadikan sebagai acuan pengambilan kebijakan dalam rangka meningkatkan motivasi latihan atlet PPLOPD Jawa Tengah.
\end{abstract}

Kata Kunci: Atlet-pelajar, Motivasi latihan, Motivasi belajar.

\section{Analysis on level of learning and training motivation among student-athletes in Central Java PPLOP 2020}

Abstract: The government through Deputy of Youth and Sport has a training center program for highschool student namely Student's Center for Education and Training (PPLOP). The program effectivity depends on the student's performance on (in training) and off the court (in education). This study aims to collect information on student motivation toward training and learning. There are 36 participants in this study. All came from team sports athletes.Descriptive quantitative percentage was used as research method which using motivation questionnaire to collect data from the participants for both training motivation $(M L)$ and learning motivation (MB).T-test was also conducted to study the variant difference on motivation between starter and subtitutes player. The results came as follow, on MB there are 47\% of the participants were categorized as highly motivated, 39\% moderately motivated and only 14\% categorized having low motivation. Meanwhile for ML, there are $11.5 \%$ of the participants are highly motivated, $77 \%$ are moderately motivated, and 11,5\% showing low level of motivation. T-test conducted among starter and subtitutes player revealed that the difference on the level of $M L$ and $M B$ were not statistically significant $(p>0.05)$ among those subjects.

Keywords: Student-athletes, Training motivation, Learning motivation

How to Cite: Syaukani, A., Subekti, N., \& Fatoni, M. (2020). Analisis tingkat motivasi belajar dan berlatih pada atlet-pelajar PPLOP Jawa Tengah tahun 2020. Jurnal Keolahragaan, 8(2), 117-125. doi:https://doi.org/10.21831/jk.v8i2.32553

\section{PENDAHULUAN}

Upaya peningkatan prestasi olahraga memang tidak lepas dari upaya pembinaan olahraga pelajar. Pembinaan atlet di usia pelajar dengan program latihan yang terstruktur dengan baik serta faktor keberlanjutan pembinaan yang jelas memiliki peran penting dalam meningkatkan prestasi olahraga nasional. Salah satu upaya pemerintah untuk melaksanakan pembinaan olahraga pelajar yakni dengan melaksana- 
kan program latihan dan latihan olahraga. Ada 2 jenjang yang telah disiapkan yakni untuk pelajar PPLOP dan untuk mahasiswa yaitu PPLM. Pemerintah pusat melalui Kementerian Pemuda dan Olahraga (Kemenpora) mendukung penuh penyelenggaraan PPLOP dan PPLM di seluruh daerah dengan memberikan dana 40 juta per anak per tahun untuk dimanfaatkan membina atlet potensial agar mahir dalam kecabangannya maupun berprestasi dalam lingkungan akademik di sekolahnya (Kemenpora, 2020).

Atlet-pelajar (student athlete) yang masuk dalam program PPLOP merupakan populasi yang unik karena mereka harus memikul 2 tanggung jawab sekaligus yakni sebagai atlet yang harus rutin berlatih dan pelajar yang harus rajin belajar. Tugas belajar mereka tunaikan melalui sekolah yang telah bekerjasama dengan Dinas Pemuda dan Olahraga (Dispora) setempat. Sedangkan rutinitas latihan biasanya dilakukan 2 kali sehari yakni setiap pagi sebelum berangkat sekolah dan sore hari setelah pulang sekolah. Aquillina (2013) dalam penelitiannya mengungkapkan bahwa setidaknya dibutuhkan waktu 20-30 jam/ minggu untuk berlatih dan bertanding agar berprestasi dalam cabang olahraga. Sedangkan dalam hal pendidikan, atlet-pelajar membutuhkan waktu setidaknya $30 \mathrm{jam} /$ minggu untuk mencapai kepuasan terhadap hasil belajar (Aquilina, 2013).

Peran sebagai atlet dan sebagai pelajar di PPLOP dijalani selama 3 tahun sebelum lulus dari SMA. Selama dalam pengasuhan PPLOP, para pelajar di PPLOP mejalani seluruh aktivitas keseharian mereka jauh dari lingkungan keluarga karena mereka diasuh dalam sistem asrama yang menuntut mereka berjarak dengan orang tua. Praktis hal tersebut memberikan tekanan tersendiri bagi para pelajar anggota PPLOP karena ketiadaan orang tua dan keluarga dekat tentu membawa beban fisik dan psikologis tersendiri bagi para pelajar terutama bagi mereka di tingkat pertama(Hyojae Kim, 2015). Dalam masa pencarian jati diri, para pelajar tentu membutuhkan bimbingan dan dukungan dari orang-orang terdekat. Ketiadaan dukungan tersebut akan berkontribusi terhadap lahirnya tekanan psikologis yang dapat mengganggu eksistensi mereka dalam bidang akademik maupun non-akademik. Selain itu tekanan juga datang dari kegiatan olahraga, atlet-pelajar harus melalui latihan yang berat dan melelahkan, harus sering bepergian untuk mengikuti kejuaraan di berbagai daerah, hingga tingginya tingkat persaingan di level yang mereka hadapi (Brown et al., 2015; Cosh \& Tully, 2015). Aktivitas keseharian yang padat, tuntutan yang tinggi dari pelatih dan guru, serta jauhnya kehidupan mereka dengan orang tua tentu berpotensi terhadap timbulnya stres di kalangan atlet-pelajar ini. Akibatnya komitmen sebagai atlet dan pelajar seringkali tidak berjalan secara ideal (Capranica \& Millard-Stafford, 2011).

Fenomena rendahnya komitmen atlet dalam memikul tanngung jawab olahraga dan akademik juga telah terdokumentasikan dengan baik melalui penelitian-penelitian terdahulu. Amerika seperti hal nya di Indonesia telah mengintegrasikan proses berlatih dan belajar seperti layaknya PPLOP di Indonesia. Namun, banyak kasus yang ditemukan bahwa atlet-pelajar Amerika kesulitan untuk meraih kesuksesan di dua aspek tersebut. Banyak dari mereka yang lebih mengutamakan prestasi olahraga ketimbang akademik(Aries et al., 2004; Gatmen, 2011). Hal yang berbeda terjadi di Eropa dimana atlet-atlet berbakat cenderung lebih mengutamakan kegiatan akademik mereka dengan dalih untuk mendapatkan masa depan yang lebih baik (Aquilina \& Henry, 2010; Lupo et al., 2015). Hal ini karena di Eropa tidak dikenal penggabungan sistem pembinaan terpadu antara olahraga dan pendidikan. Institusi pendidikan fokus mengembangkan kapasitas akademik siswa, sedangkan urusan olahraga diserahkan kepada klub untuk melakukan pembinaan.

Sejatinya komitmen atlet untuk terus berlatih dan pelajar untuk tekun belajar sangat bergantung dari tingkat motivasi yang dimiliki (Cece et al., 2018; Tasiwan et al., 2014). Seseorang yang tidak memiliki dorongan, gairah, dan semangat untuk melakukan sesuatu dikategorikan sebagai amotivasi. Sebaliknya orang yang penuh semangat, dan enerjik dalam menyelesaikan sebuah pekerjaan dikategorikan sebagai orang yang termotivasi (Ryan \& Deci, 2000). Motivasi secara sederhana didefinisikan sebagai dorongan psikologis untuk melakukan sesuatu. Motivasi diklasifikasikan menjadi 2 jenis yakni motivasi intrinsik (berasal dari dalam diri sendiri, rasa senang muncul ketika melakukan sesuatu) maupun ekstrinsik (misalnya hadiah yang diberikan semakin mendorong seseorang untuk melakukan sesuatu) (Lazowski \& Hulleman, 2016). Pada praktiknya, motivasi antara orang yang satu dengan lainnya akan sangat bervariasi baik itu dalam tingkatannya maupun dari sumber motivasinya (Ryan \& Deci, 2000).

Penelitian-penelitian sejenis di Indonesia sebenarnya telah banyak ditemui, namun masih sedikit yang fokus secara bersamaan pada motivasi olahraga dan belajar pada atlet-pelajar yang tergabung dalam program PPLOP (Dimyati et al., 2013; Muskanan, 2015). Tanggung jawab ganda yang diperankan oleh atlet PPLOP tentu membutuhkan perhatian yang holistik agar masalah yang terkait dengan 
rendahnya motivasi belajar dan berlatih dapat diidentifikasi dan diselesaikan secara bersamaan dan terintegrasi. Oleh karenanya, penelitian ini bertujuan untuk mengidentifikasi tingkat motivasi atlet-pelajar dalam berlatih dan belajar sebagai bagian dari kajian global yang memetakan fenomena psikologis yang terjadi pada atlet-atlet pelajar di Indonesia khususnya di wilayah Jawa Tengah yang tergabung ke dalam PPLOP.

\section{METODE}

Penelitian ini menggunakan metode kuantitatif deskriptif presentase. Dalam penelitian ini, peneliti mencoba untuk menggambarkan dan menginterpretasikan motivasi atlet pelajar dalam berlatih di lapangan dan belajar di kelas. Sebanyak 36 atlet PPLOP dari 3 cabang olahraga beregu yakni sepakbola, bola basket dan bola voli dilibatkan dalam penelitian ini sebagai sampel penelitian. Hal ini dikarenakan mayoritas atlet PPLOP Jawa Tengah merupakan atlet olahraga beregu. Selain itu, adanya pemain inti dan pemain cadangan pada cabang olahraga beregu memungkinkan peneliti untuk mempelajari karakteristik motivasi di dua kelompok tersebut. Diketahui dalam sebuah studi bahwa pemain dengan fisik dan kemampuan bermain yang berada diatas rata-rata rekan satu tim nya akan memiliki kecenderungan untuk menjadi pemain inti (Sell et al., 2018). Namun belum diungkapkan adakah perbedaan profil psikologis antara pemain inti dan pemain cadangan dalam sebuah tim. Olehkarena itu penelitian ini berusaha untuk melengkapi kajian tersebut dengan menggali karakteristik motivasi antara kelompok pemain inti dan pemain cadangan. Dasar penentuan sampel menggunakan metode purposive sampling di mana hanya atlet dalam cabang olahraga beregu yang dapat dijadikan sebagai sampel penelitian. Hal ini erat kaitannya dengan minat peneliti untuk turut mengidentifikasi perbedaan tingkat motivasi antara pemain inti dengan pemain cadangan.

Variabel pada peneltian ini adalah motivasi belajar (MB) dan motivasi berlatih (ML). Instrumen penelitian yang digunakan pada variabel MB yaitu kuesioner yang dibuat berdasarkan kisi-kisi yang terkait dengan aktivitas, dorongan, dan hambatan yang mungkin dialami oleh seorang pelajar. Selanjutnya kisi-kisi tersebut disusun menjadi 38 butir pertanyaan dan diujikan kepada subyek lain diluar populasi penelitian. Uji coba dilakukan dengan maksud untuk memastikan bahwa kuesioner yang dibuat memenuhi kelayakan untuk digunakan dalam penelitian (valid dan reliabel). Hasil uji coba menghasilkan nilai alpha cronbach sebesar 0,884 dengan nilai r $>0,6$ sehingga kuesioner MB dianggap reliabel dan siap untuk digunakan sebagai instrumen penelitian

Adapun untuk variabel motivasi berlatih (ML) digunakan kuesioner dalam bahasa indonesia yang mengadopsi Sport Motivation Scale yang mencakup aspek motivasi ekstrinsik, motivasi intrinsik, dan kondisi amotivasi (Pelletier et al., 1995). Pengambilan data dilakukan dengan memakai metode crosssectional surveys yang mana pengisian kedua jenis kuesioner dilakukan dalam waktu yang bersamaan. Kuesioner dikemas dalam bentuk daring dan dapat diakses secara bersamaan oleh subjek. Pembagian akses kuesioner dilakukan di bawah koordinasi pelatih masing-masing cabang olahraga. Pelatih sekaligus memastikan setiap atlet melengkapi seluruh informasi yang dibutuhkan. Kuesioner dikuantifikasikan dengan menggunakan Skala Likert. Respon kuesioner yang dihasilkan untuk MB dan ML kemudian diinterpretasikan menggunakan statistik deskriptif kuantitatif dan hasilnya dikategorikan menjadi 3 kategori yakni rendah, sedang, dan tinggi (Arikunto, 2010).

Uji beda dilakukan dengan menggunakan metode Independent Sample T-test untuk mengetahui adanya signifikansi perbedaan varian dari pemain inti dan pemain cadangan. Uji prasyarat juga dilakukan sebelum dilakukan uji beda untuk memastikan bahwa data layak diolah menggunakan statistik parametrik. Seluruh operasi statistik dilakukan dengan menggunakan software IBM SPSS Statistic $23^{\circledR}$.

\section{HASIL DAN PEMBAHASAN}

\section{Hasil}

Motivasi Belajar

Hasil analisis terhadap hasil rata-rata kuesioner motivasi belajar atlet menunjukkan valid, reliabel, serta memenuhi syarat berdistribusi normal dan memiliki varian yang homogen. Berikut ini deskripsi statistik dari nilai motivasi belajar atlet PPLOP Jawa Tengah (Tabel.1). 
Jurnal Keolahragaan 8 (2), 2020 - 120

Agam Akhmad Syaukani, Nur Subekti, Muhad Fatoni

Tabel 1. Tingkat Motivasi Belajar Atlet PPLOP Jawa Tengah Tahun 2020

\begin{tabular}{|c|c|}
\hline Dimensi & Motivasi Belajar (MB) \\
\hline Jumlah atlet (n) & 36 \\
\hline Skor maksimal & 170 \\
\hline Skor minimal & 115 \\
\hline Mean & 139 \\
\hline Standar deviasi & 12,14 \\
\hline Pemain inti (n) & 23 \\
\hline Cadangan (n) & 13 \\
\hline Mean inti & 138,26 \\
\hline Mean cadangan & 140,31 \\
\hline Sig. & 0,634 \\
\hline
\end{tabular}

Berdasarkan proses penelitian didapati tingkat motivasi belajar (MB) atlet PPLOP Jawa Tengah terbagi ke dalam tiga kategori dengan presentase tertinggi pada kategori motivasi tinggi sebesar $47 \%$, disusul motivasi sedang dengan 39\%, dan motivasi rendah sebesar $14 \%$ sebagaimana ditunjukkan pada Gambar 1. Selain itu dari tampilan data tabel nilai deskriptif (Tabel 1) terdapat perbedaan rata-rata capaian motivasi belajar antara pemain inti dan pemain cadangan, namun hasil uji beda (independent sample $t$-test) menunjukkan perbedaan tersebut tidak signifikan secara statistik ( $\mathrm{p}>0,05)$.

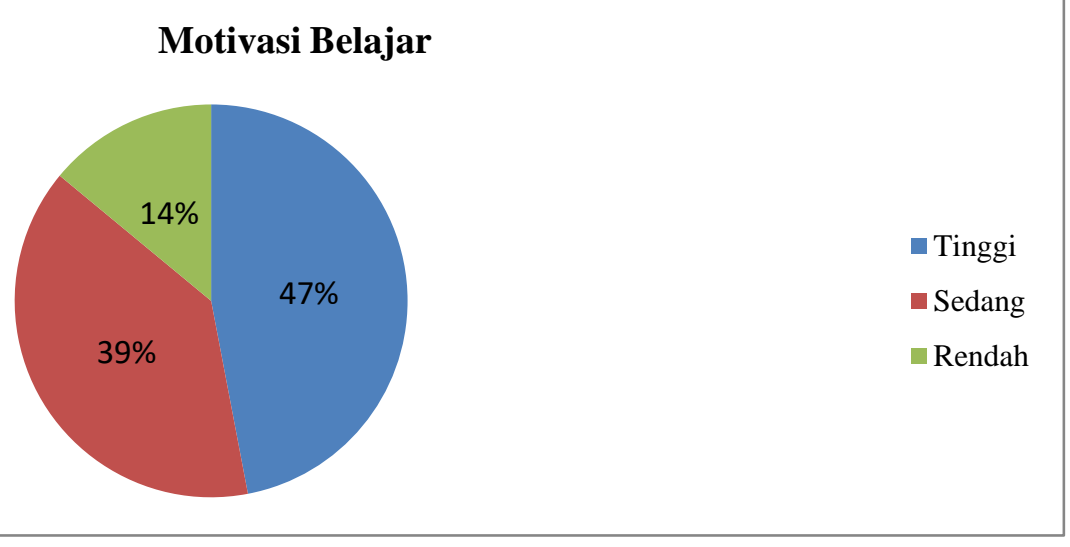

Gambar 1. Diagram Pie Presentase Tingkat Motivasi Belajar Atlet dalam 3 Kategori

Data penelitian menunjukkan bahwa tingkat motivasi belajar atlet PPLOP dalam kondisi yang relatif baik, artinya mayoritas atlet terpantau memiliki motivasi dan semangat belajar yang tinggi (47\%). Akan tetapi, jika berkaca pada masih terdapatnya atlet dengan motivasi belajar rendah (14\%) dan besarnya presentase atlet dengan motivasi belajar sedang (39\%) relatif terhadap presentase motivasi dari 2 kategori yang lain maka diperlukan langkah tindak lanjut sebagai upaya untuk menaikkan tingkat motivasi belajar atlet. Hal ini karena tingkat motivasi berhubungan langsung dengan capaian pembelajaran siswa. Semakin tinggi tingkat motivasi seorang siswa, semakin tinggi pula kecenderungannya untuk berprestasi di kelas (Lazowski \& Hulleman, 2016).

Meningkatkan motivasi atlet PPLOP dalam belajar dapat dimulai dengan melakukan rekayasa pembelajaran di kelas. Salah satu metode yang populer dapat menarik ketertarikan siswa untuk belajar adalah metode active learning (Sukma \& Ibrahim, 2016). Melalui metode active learning atlet akan diajak untuk lebih aktif dalam belajar di kelas, baik itu aktif dalam hubungannya dengan sesama teman maupun hubungannya dengan guru. Pembelajaran ini muaranya akan membimbing atlet untuk mandiri dalam memperoleh pengetahuan di mana peran guru hanya sebagai fasilitator yang memastikan setiap topik yang dipelajari dapat secara sempurna dipahami oleh anak didiknya. Silberman (2006) mengungkapkan hanya dengan membuat siswa aktif dalam memecahkan permasalahan di kelas akan mampu mengoptimalkan pengetahuan yang didapat oleh siswa. Hal ini tentunya akan efektif jika diterapkan di kelas filial PPLOP karena stamina yang terkuras selama latihan akan membuat konsentrasi siswa menurun. Kondisi semacam ini tentu akan membuat pembelajaran yang bersifat satu arah berjalan secara tidak efektif karena stamina yang menurun dan kelelahan setelah latihan akan membuat hilangnya konsentrasi siswa dalam meyimak isi pelajaran sehingga tingkat pemahaman siswa pun akan terbatas. 
Jurnal Keolahragaan 8 (2), 2020 - 121

Agam Akhmad Syaukani, Nur Subekti, Muhad Fatoni

Rutinitas atlet PPLOP didominasi oleh 2 kewajiban utama yaitu berlatih dan belajar. Rutinitas latihan hampir selalu diawali di pagi hari sebelum atlet pergi belajar di sekolah. Tekanan yang berasal dari padatnya jadwal dan porsi latihan dapat memicu kejenuhan pada atlet (sport burnout). Burnout pada atlet bersifat multidimensional yang artinya merupakan gabungan dari kelelahan fisik maupun mental yang dapat berakibat menurunnya performa atlet dan beresiko menurunkan motivasi meraih prestasi (Gotwals, 2011). Kelelahan berpengaruh terhadap tingkat konsentrasi ketika pembelajaran kelas berlangsung. Hilang atau menurunnya konsentrasi disertai dengan menurunnya tingkat motivasi karena kelelahan dilaporkan oleh beberapa penelitian (Picariello et al., 2016; Rimes et al., 2016; Schakel et al., 2019; Sorkkila et al., 2017). Salah satu metode untuk mengatasi menurunnya konsentrasi belajar yaitu dengan menggunakan metode belajar sambil bermain (gamification learning). Metode ini mengajak siswa untuk belajar dalam bingkai sebuah permainan di mana ada kompetisi, aturan, dan sistem reward yang dipersiapkan. Model pembelajaran seperti ini selain meningkatkan motivasi, juga mampu untuk meningkatkan konsentrasi belajar karena suasana yang menyenangkan selama pembelajaran. Buckley dan Doyle (2016) mengungkapkan bahwa modification learning berdampak positif pada motivasi belajar siswa dan efeknya sangat bervariasi tergantung dari apakah siswa termotivasi secara intrinsik atau ekstrinsik.

Motivasi Latihan

Hasil analisis terhadap hasil rata-rata kuesioner motivasi latihan atlet menunjukkan valid, reliabel, serta memenuhi syarat berdistribusi normal dan memiliki varian yang homogen. Berikut ini deskripsi statistik dari nilai motivasi belajar atlet PPLOP Jawa Tengah (Tabel 2).

Tabel 2. Tingkat Motivasi Latihan Atlet PPLOP Jawa Tengah Tahun 2020

\begin{tabular}{|c|c|}
\hline Dimensi & Motivasi Latihan (ML) \\
\hline Skor maksimal & 194 \\
\hline Skor minimal & 148 \\
\hline Mean & 179,15 \\
\hline Standar deviasi & 10,98 \\
\hline Mean inti & 182,13 \\
\hline Mean cadangan & 175,09 \\
\hline Sig. & 1,07 \\
\hline
\end{tabular}

Berdasarkan klasifikasi diketahui presentase atlet PPLOP Jawa Tengah dengan motivasi berlatih tinggi sebanyak $11 \%$, motivasi berlatih sedang sebanyak $77 \%$, dan motivasi berlatih rendah sebanyak $12 \%$ sebagaimana dapat dilihat pada Gambar 2. Selain itu dari tampilan data tabel nilai deskriptif (Tabel 2) terdapat perbedaan rata-rata capaian motivasi latihan antara pemain inti dan pemain cadangan, namun hasil uji beda (independent sample t-test) menunjukkan perbedaan tersebut tidak signifikan secara statistik $(\mathrm{p}>0,05)$.

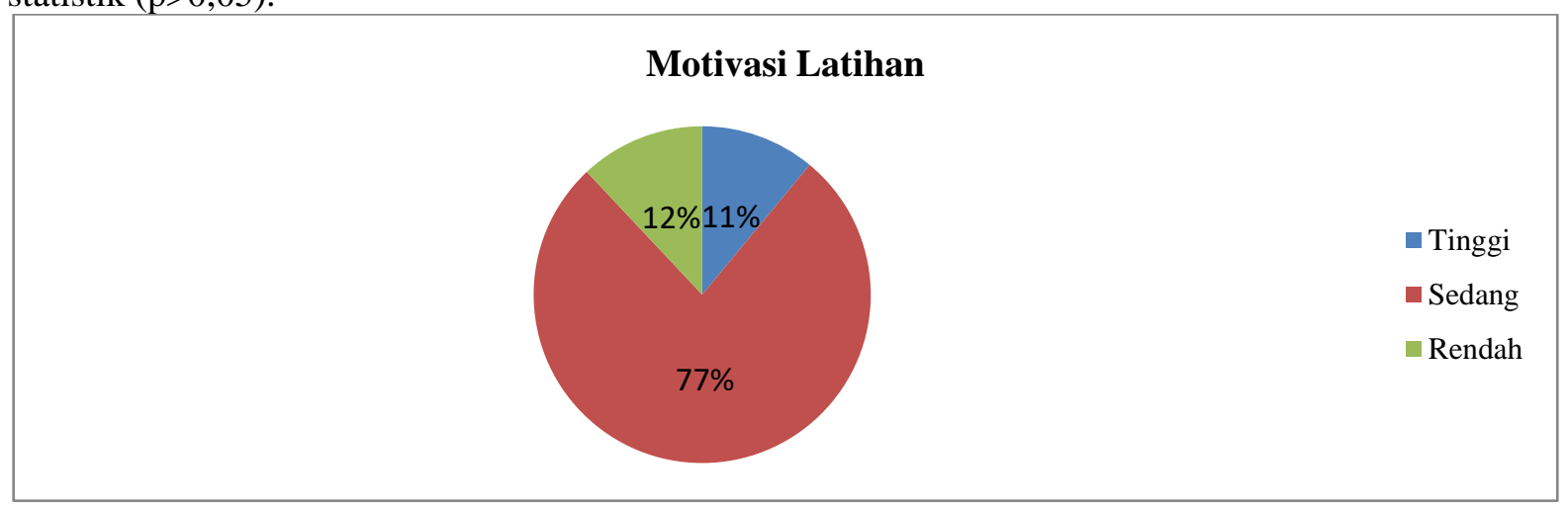

Gambar 2. Diagram Pie Presentase Tingkat Motivasi Latihan Atlet dalam 3 Kategori

Data penelitian menunjukkan bahwa mayoritas atlet PPLOP Jawa Tengah memiliki tingkat motivasi berlatih sedang (77\%). Hanya $11 \%$ atlet yang memiliki motivasi berlatih tinggi. Hal ini tentu sangat disayangkan mengingat presentase atlet dengan motivasi tinggi justru merupakan minoritas. Perlu dilakukan upaya untuk meningkatkan tingkat motivasi atlet dalam berlatih karena tingginya tingkat motivasi tentunya akan berdampak terhadap meningkatnya daya saing atlet dalam meraih prestasi olahraga. 
Dalam teori psikologi olahraga, para ahli telah sepakat jika tingkat motivasi akan sangat berperan terhadap prestasi atlet. Atlet yang memiliki motivasi tinggi akan berlatih dengan keras, berupaya semaksimal mungkin untuk memenangkan persaingan dan mengukir prestasi setinggi-tingginya (Adeyeye et al., 2013).

Konsep psikologis yang membahas tentang keinginan, dorongan, kemauan, dan minat adalah motivasi. Seseorang yang termotivasi cenderung akan menampilkan karakteristik sebagai berikut: (1) Memiliki semangat dan gairah yang tinggi untuk melakukan sesuatu; (2) Mengarahkan semua usaha dan perhatian untuk mencapai prestasi; dan (3) Mempunyai perasaan dengan derajat yang berbeda untuk setiap tujuan yang dicapai (Kaya et al., 2015). Olehkarenanya penting bagi seorang atlet untuk selalu termotivasi, sehingga dapat memiliki dorongan yang kuat untuk terus berlatih apapun halangan dan rintangannya.

Berbagai peran dapat dilakukan untuk memompa semangat atlet dan meningkatkan motivasi mereka untuk berlatih dan bertanding. Teori motivasi membagi jenis motivasi ke dalam dua kategori umum yaitu motivasi intrinsik dan motivasi ekstrinsik. Motivasi intrinsik merupakan dorongan yang timbul dari dalam individu untuk melakukan sesuatu karena perasaan senang akan muncul dari aktivitas itu, sedangkan motivasi ekstrinsik merupakan peran stimulus eksternal termasuk peran lingkungan sekitar untuk mendorong seseorang meelakukan sesuatu. Orang yang termotivasi secara eksternal akan mencapai kepuasan dan kebanggaan dari apa yang dilakukan karena mampu mendapat pengakuan dan hadiah sebagai imbalan atas apa yang telah dicapai dan dikerjakan (Pelletier et al., 1995; Ryan \& Deci, 2000).

Menumbuhkan motivasi ekstrinsik dapat diawali dengan mengoptimalkan kondisi lingkungan sekitar atlet. Peranan lingkungan sekitar berasal salah satunya berasal dari lingkungan sosial terdekat atlet. Salah satu yang berpengaruh adalah pelatih. Kondisi keseharian atlet PPLOP yang tinggal di asrama dan jauh dari orang tua membuat peran pelatih dalam membentuk psikologis atlet amatlah penting. Menurut teori determinasi mandiri atau self-determination theory atlet cenderung menyukai figur pelatih yang suportif dan otonom. Menurut teori ini pelatih yang otoriter dan memaksakan tujuannya secara frontal kepada atlet akan mengakibatkan psikologis atlet tertekan dan menyebabkan kondisi amotivasi pada atlet. Pelatih dengan kriteria otonom dan suportif mengutamakan komunikasi dua arah dengan atletnya, memposisikan dirinya selain sebagai pelatih juga sebagai teman, dan orang tua. Pelatih mengarahkan atlet kearah tujuan yang ingin dicapainya, menghormati pilihan atlet dan menggunakan bahasa yang persuasif serta informatif dalam berkomunikasi. Pelatih juga menampung keluh kesah atlet dan membantu memecahkan masalahnya (Ryan \& Deci, 2017). Meskipun terkesan 'bebas' dan demokratis, pelatih juga tetap berkewajiban memastikan perkembangan atletnya selalu berada dalam tren positif.

Motivasi intrinsik diasosiasikan sebagai dorongan individu yang muncul akibat rasa senang atas aktivitas yang dijalankannya. Penting bagi atlet untuk menumbuhkan semangat dari dalam diri mereka. Hal ini karena dorongan yang berasal dari dalam diri sendiri (motivasi intrinsik) mampu bertahan lebih lama jika dibandingkan dengan dorongan dari luar atau motivasi eksternal (Ryan \& Deci, 2000). Atlet yang termotivasi secara intrinsik menunjukkan gejala positif secara psikologis seperti perasaan bebas dari tekanan sehingga yang dilakukan atlet dalam latihan maupun pertandingan merupakan usaha terbaiknya (Blegur \& Mae, 2018). Menumbuhkan motivasi intrinsik dapat dilakukan dengan mengajak atlet untuk berkontemplasi merenungkan tujuan perjalanan hidupnya dan apa yang dijalankannya sekarang. Pemahaman akan tujuan hidup dan peran dalam lingkungan sosial akan membuat atlet merasa apa yang dilakukan selama latihan maupun pertandingan adalah bagian dari upaya merintis masa depan yang cemerlang. Deskripsi positif dalam benak atlet atas apa yang dilakukan tentu akan melahirkan kerelaan, kepuasan, dan rasa senang ketika berlatih maupun bertanding.

Motivasi baik yang bersifat ekstrinsik maupun intrinsik sangat penting untuk menjadi atribut psikologis atlet. Kurangnya perhatian terhadap atlet dapat berakibat atlet kehilangan motivasi. Atlet yang tidak termotivasi cenderung menarik diri dari kegiatan yang dilakukannya karena hilangnya rasa nyaman dan persepsi negatif serta hilangnya kontrol akan apa yang dilakukannya (Barkoukis et al., 2008). Kondisi semacam ini jika dibiarkan berlanjut tentu akan berdampak pada menurunnya prestasi atlet, dan dalam kondisi tertentu dapat merusak kohesi tim olahraga yang bersangkutan.

Beberapa penelitian telah mengingat kondisi yang dialami oleh atlet PPLOP dimana fasilitas tempat tinggal, kebutuhan pokok hidup dan sekolah sudah difasilitasi pemerintah tentunya pendekatan yang paling ideal adalah meningkatkan motivasi atlet secara intrinsik. Motivasi intrinsik jika dibandingkan 
Jurnal Keolahragaan 8 (2), 2020 - 123

Agam Akhmad Syaukani, Nur Subekti, Muhad Fatoni

dengan motivasi ekstrinsik akan dapat bertahan lebih lama karena bersumber dari kesadaran pribadi atlet bahwa apa yang dilakukannya itu penting dan layak untuk diperjuangkan secara maksimal.

\section{SIMPULAN}

Penelitian ini menemukan bahwa sebagian besar atlet PPLOP Jawa Tengah memiliki motivasi yang tinggi dalam belajar ( $47 \%$ ) dan hanya sebagian kecil yang memiliki motivasi akademik yang rendah (14\%). Hasil ini mengindikasikan bahwa manajemen pembelajaran di lingkungan PPLOP Jawa Tengah telah berjalan dengan sebagaimana mestinya. Setidaknya menurut Sutama dkk (2012) motivasi belajar siswa akan tumbuh melalui manajemen pembelajaran yang baik. Lebih jauh, studi tersebut menyebutkan setidaknya ada 3 parameter manajemen pembelajaran yang mempengaruhi hasil belajar siswa yakni (1) pengelolaan kelas dan media pembelajaran, (2) pengelolaan bahan pembelajaran serta (3) pengelolaan interaksi. Uji beda dalam sampel antara pemain inti dan pemain cadangan menunjukkan data yang secara deskriptif berbeda tidak bermakna signifikan secara statistik. Artinya, tidak ada perbedaan yang signifikan antara motivasi belajar pemain inti dan pemain cadangan.

Pada analisis motivasi berlatih ditemukan fakta bahwa mayoritas atlet (77\%) memiliki tingkat motivasi berlatih yang sedang. Atlet yang memiliki motivasi tinggi dalam berlatih tergolong minoritas dengan presentase sebesar $11 \%$ dari total sampel. Artinya, perlu upaya yang serius dari pihak yang berwenang untuk memperbaiki semangat, kepercayaan diri, dan dorongan untuk berlatih melalui pendekatan yang bersifat persuasif. Uji beda yang dilakukan dalam sampel menyatakan tidak ada perbedaan signifikan antara tingkat motivasi pemain inti dan pemain cadangan. Perlu langkah holistik yang ditujukan untuk seluruh atlet PPLOP Jawa tengah agar semakin termotivasi dalam berlatih. Harapannya atlet-atlet PPLOP Jawa tengah mampu menjadi teladan bagi anak-anak seusianya untuk dapat berprestasi di dalam dan di luar kelas melalui kegiatan-kegiatan akademik dan keolahragaan.

\section{DAFTAR PUSTAKA}

Adeyeye, F. M., Vipene, J. . B., \& Asak, D. A. (2013). The impact of motivation on athletic achievement: a case study of the 18th National Sports Festival, Lagos, Nigeria. Academic Research International, 4(5), 378-383. http://www.savap.org.pk/journals/ARInt./Vol.4(5)/2013(4.5-37).pdf

Aquilina, D. (2013). A study of the relationship between elite athletes' educational development and sporting performance. The International Journal of the History of Sport, 30(4), 374-392. https://doi.org/10.1080/09523367.2013.765723

Aquilina, D., \& Henry, I. (2010). Elite athletes and university education in Europe: a review of policy and practice in higher education in the European Union Member States. International Journal of Sport Policy and Politics, 2(1), 25-47. https://doi.org/10.1080/19406941003634024

Aries, E., McCarthy, D., Salovey, P., \& Banaji, M. R. (2004). A comparison of athletes and nonathletes at highly selective colleges: academic performance and personal development. Research in Higher Education, 45(6), 577-602. https://doi.org/10.1023/B:RIHE.0000040264.76846.e9

Arikunto, S. (2010). Prosedur penelitian: Suatu pendekatan praktik. Rineka Cipta.

Barkoukis, V., Tsorbatzoudis, H., Grouios, G., \& Sideridis, G. (2008). The assessment of intrinsic and extrinsic motivation and amotivation: Validity and reliability of the Greek version of the Academic Motivation Scale. Assessment in Education: Principles, Policy \& Practice, 15(1), 39-55. https://doi.org/10.1080/09695940701876128

Blegur, J., \& Mae, R. M. (2018). Motivasi berolahraga atlet atletik dan tinju. Jurnal Keolahragaan, 6(1), 29-37. https://doi.org/10.21831/jk.v6i1.16150

Brown, D. J., Fletcher, D., Henry, I., Borrie, A., Emmett, J., Buzza, A., \& Wombwell, S. (2015). A British university case study of the transitional experiences of student-athletes. Psychology of Sport and Exercise, 21, 78-90. https://doi.org/10.1016/j.psychsport.2015.04.002

Buckley, P., \& Doyle, E. (2016). Gamification and student motivation. Interactive Learning Environments, 24(6), 1162-1175. https://doi.org/10.1080/10494820.2014.964263

Capranica, L., \& Millard-Stafford, M. L. (2011). Youth sport specialization: How to manage 
Jurnal Keolahragaan 8 (2), 2020 - 124

Agam Akhmad Syaukani, Nur Subekti, Muhad Fatoni

competition and training? International Journal of Sports Physiology and Performance, 6(4), 572-579. https://doi.org/10.1123/ijspp.6.4.572

Cece, V., Lienhart, N., Nicaise, V., Guillet-Descas, E., \& Martinent, G. (2018). Longitudinal sport motivation among young athletes in intensive training settings: The role of basic psychological needs satisfaction and thwarting in the profiles of motivation. Journal of Sport and Exercise Psychology, 40(4), 186-195. https://doi.org/10.1123/jsep.2017-0195

Cosh, S., \& Tully, P. J. (2015). Stressors, coping, and support mechanisms for student athletes combining elite sport and tertiary education: implications for practice. The Sport Psychologist, 29(2), 120-133. https://doi.org/10.1123/tsp.2014-0102

Dimyati, D., Herwin, H., \& Hastuti, T. A. (2013). Karakteristik psikologis atlet di Pusat Pendidikan dan Latihan Pelajar (PPLP). Jurnal Psikologi UGM, 40(2), 143-158. https://doi.org/10.22146/jpsi.6973

Gatmen, E. J. P. (2011). Academic exploitation: The adverse impact of college athletics on the educational success of minority student-athletes. Seattle Journal of Social Justice, 10(1), 509583. https://heinonline.org/HOL/LandingPage?handle=hein.journals/sjsj10\&div=19\&id=\&page=

Gotwals, J. K. (2011). Perfectionism and burnout within intercollegiate sport: A person-oriented approach. The Sport Psychologist, 25(4), 489-510. https://doi.org/10.1123/tsp.25.4.489

Hyojae Kim, S. K. (2015). Psychological and emotional stress among the students living in dormitory: A comparison between normal and depressive students. Journal of Sleep Disorders \& Therapy, 04(03), 6-11. https://doi.org/10.4172/2167-0277.1000201

Kaya, S., Kabakçi, A. C., \& Doğan, A. A. (2015). Differences in motivation for participating sport activities according to sport branches. International Journal of Science Culture and Sport, 3(9), 44-44. https://doi.org/10.14486/IJSCS229

Lazowski, R. A., \& Hulleman, C. S. (2016). Motivation interventions in education. Review of Educational Research, 86(2), 602-640. https://doi.org/10.3102/0034654315617832

Lupo, C., Guidotti, F., Goncalves, C. E., Moreira, L., Doupona Topic, M., Bellardini, H., Tonkonogi, M., Colin, A., \& Capranica, L. (2015). Motivation towards dual career of European studentathletes. European Journal of Sport Science, 15(2), 151-160. https://doi.org/10.1080/17461391.2014.940557

Muskanan, K. (2015). Analisis Motivasi Berprestasi Atlet Pusat Pendidikan dan Latihan Olahraga Pelajar Provinsi Nusa Tenggara Timur. JKAP (Jurnal Kebijakan Dan Administrasi Publik), 19(2), 105. https://doi.org/10.22146/jkap.7608

Pelletier, L. G., Tuson, K. M., Fortier, M. S., Vallerand, R. J., Briére, N. M., \& Blais, M. R. (1995). Toward a new measure of intrinsic motivation, extrinsic motivation, and amotivation in sports: The sport motivation scale (SMS). Journal of Sport and Exercise Psychology, 17(1), 35-53. https://doi.org/10.1123/jsep.17.1.35

Picariello, F., Moss-Morris, R., Macdougall, I. C., \& Chilcot, J. (2016). The role of psychological factors in fatigue among end-stage kidney disease patients: a critical review. Clinical Kidney Journal, 10(1), sfw113. https://doi.org/10.1093/ckj/sfw113

Rimes, K. A., Ashcroft, J., Bryan, L., \& Chalder, T. (2016). Emotional suppression in chronic fatigue syndrome: Experimental study. Health Psychology, 35(9), 979-986. https://doi.org/10.1037/hea0000341

Ryan, R. M., \& Deci, E. L. (2000). Intrinsic and extrinsic motivations: Classic definitions and new directions. Contemporary Educational Psychology, 25(1), 54-67. https://doi.org/https://doi.org/10.1006/ceps.1999.1020

Ryan, R. M., \& Deci, E. L. (2017). Self-determination theory: Basic psychological needs in motivation, development, and wellness. Guilford Press.

Schakel, W., Bode, C., van de Ven, P. M., van der Aa, H. P. A., Hulshof, C. T. J., van Rens, G. H. M. B., \& van Nispen, R. M. A. (2019). Understanding fatigue in adults with visual impairment: A path analysis study of sociodemographic, psychological and health-related factors. PLOS ONE, 
Jurnal Keolahragaan 8 (2), 2020 - 125

Agam Akhmad Syaukani, Nur Subekti, Muhad Fatoni

14(10), e0224340. https://doi.org/10.1371/journal.pone.0224340

Sell, K. M., Prendergast, J. M., Ghigiarelli, J. J., Gonzalez, A. M., Biscardi, L. M., Jajtner, A. R., \& Rothstein, A. S. (2018). Comparison of physical fitness parameters for Starters vs. Nonstarters in an NCAA Division I Men's Lacrosse Team. Journal of Strength and Conditioning Research, 32(11), 3160-3168. https://doi.org/10.1519/JSC.0000000000002830

Silberman, M. (2006). Active learning 101 cara belajar siswa aktif. Nusamedia.

Sorkkila, M., Aunola, K., \& Ryba, T. V. (2017). A person-oriented approach to sport and school burnout in adolescent student-athletes: The role of individual and parental expectations. Psychology of Sport and Exercise, 28, 58-67. https://doi.org/10.1016/j.psychsport.2016.10.004

Sukma, M. C., \& Ibrahim, M. (2016). Developing materials for active learning of guided inquiryintegrated bowling campus on the topic of sense of hearing and sonar system of living organism. Jurnal Pendidikan IPA Indonesia, 5(2), 256-260. https://doi.org/10.15294/jpii.v5i2.5981

Sutama, S., Narimo, S., \& Haryoto, H. (2012). Pengelolaan pembelajaran matematika pascabencana erupsi Merapi. Jurnal Kependidikan: Penelitian Inovasi Pembelajaran, 42(1), 7-17. https://doi.org/10.21831/jk.v42i1.2227

Tasiwan, Nugroho, S. E., \& Hartono. (2014). Analisis tingkat motivasi siswa dalam pembelajaran IPA model advance organizer berbasis proyek. Jurnal Pendidikan IPA Indonesia, 3(1), 43-50. https://doi.org/10.15294/jpii.v3i1.2900 